\title{
STRENGTHENING OF REINFORCED CONCRETE BEAM STRUCTURES USING EXTERNAL REINFORCEMENT. EFFICIENCY RESEARCH
}

\section{Molodid A. S.}

\section{INTRODUCTION}

Along with the development of the latest technologies in the construction of new structures, the reconstruction and major overhaul of existing buildings is also an important part of the construction complex, which needs improvement. One of the most common types of construction works performed during the renovation of buildings is the strengthening of reinforced concrete beam structures, namely: crossbars, floor slabs, coverings, beams, etc. Usually, in practice, to strengthen these structures, the following methods are used: increase in cross-section due to build-up; change of static scheme of work due to installation of tighteners, struts, racks, etc. ${ }^{1}$. However, sometimes the installation of additional, bulky, reinforcement designs is unacceptable because it causes changes in construction design and layout decisions of the interior space of the building at the same time significantly increasing the load on the bearings and the foundations.

In this case, the method of reinforcing structures through external reinforcement is quite effective and advisable ${ }^{2}$. The principle of such

${ }^{1}$ DSTU B V.3.1-2: 2016. Repair and strengthening of bearing and enclosing building constructions and foundations of buildings and structures [Effective from 2017-04-01]. - Kyiv: SE "UkrNDNTS", 2017. - 72 p.; Ignatova I.V. Strengthening of concrete structures with the help of a polymer-silicate composition / I.V. Ignatova // Building Constructions: a collection of scientific works. - Kyiv, SE "NDIBK", 2011. - Issue number 75, Book 2. - pp. 614 - 621.; Rekomendatsyy po vosstanovlenyyu y usylenyyu polnosbornykh zdanyy polymerrastvoramy. [Recommendations for the restoration and strengthening of full-fledged buildings by polymer materials] TbilZNIIEP. - Moscow: Stroyizdat, 1990. - 160 p.; Minnaugh P. L. The experimental behavior of steel fiber reinforced polymer retrofit measures: thesis master of Science / Patrick Lucien Minnaugh; University of Pittsburgh school of engineering. Pittsburgh, $2006-113$ p.

${ }^{2}$ Rekomendatsyy po vosstanovlenyyu y usylenyyu polnosbornykh zdanyy polymerrastvoramy. [Recommendations for the restoration and strengthening of full-fledged buildings by polymer materials] TbilZNIIEP. - Moscow: Stroyizdat, 1990. - 160 p.; Savyovsky V. V. reconstruction of buildings and constructions / V. V. Savyovsky - Kiev, «Lira-K», 2018. - 320 p.; Savyovsky V. V. Strengthening of reinforced concrete beam structures by external reinforcement / V.V. Savyovsky, O. S. Molodid, N.O. Malets // Development Management of complex systems. - 2017 - № 29. pp. 198 - 204.; Grigorovsky P. E. Strengthening of beam structures by external reinforcement by the 
reinforcement consists in glueing additional reinforcement in the form of high-strength cloths, plates or strips (lamels) using special glues on the surface of reinforced structures ${ }^{3}$, Fig. 1. Both metal and composite materials based on carbon fibers and fiberglass are used as external reinforcement ${ }^{4}$.

Exterior reinforcement technology has several advantages over classic techniques, because of the simplicity of the work; the reinforcement elements do not overload the structure as they have a relatively small mass and do not change the design and layout solutions of the interior spaces. The high cost of carbon materials can be attributed to the disadvantages of this technology.

During the inspection of the 5-storey frame-monolithic building in Kiev, a number of damages and defects of structures of inter-storey monolithic reinforced concrete floors were revealed. Numerous damages in the form of cracks located in the stretched zones of beam structures were found on the surface of building structures of beams and slabs of floor-to-ceiling slabs. It was found that the damage was formed as a result of the influence of structural, technological and operational factors, in particular: insufficient reinforcement of stretched zones; overload of structures; discrepancy of thickness of a protective layer to design decisions and normative requirements; durability of concrete is lower than specified in the project; thickness of a slab, in separate places, is less than design; probable early the formwork can be removed.

After cleaning by sandblasting the lower surface of one floor slab, the directions of formation of cracks of their length and width of disclosure are established (Fig. 1,2). Cracks are mainly located along the lower working armature in the protective layer of the stretched zone of the structure. The total length of cracks on the specified slab floor area of $250 \mathrm{~m} 2$ was approximately $368 \mathrm{~m}$. p., including:

Three monolithic reinforced concrete beams, which take the load from the walls, enclosing the landing of all floors located above, were found on the section of the basement floor overlap. Vertical and inclined cracks with

method of adhesion of high-strength fabrics / P. E. Grigorovsky, O. S. Molodid, R. O. Plokhuta // Building Production. - 2016 - No. 61/1. - pp. 13 - 18 .

${ }^{3}$ Technological map for the restoration of brick and reinforced concrete structures and their protection / LLC «Composite». - Kyiv, 2009. - 7 p.; Shagin A.L. Reconstruction of buildings and structures / A.L. Shagin, Yu. V. Bondarenko, D.F. Goncharenko. - Moscow, Higher Education, 1991. - 352 p.; Obaidat Y. T. Structural retrofitting of reinforced concrete beams using carbon fibre reinforced polymer: Licentiate Dissertation / Yasmeen Taleb Obaidat; Division of Structural Mechanics, LTH, Lund University. - Sweden, May, 2010 - 88 p. ISSN 0281-6679

${ }^{4}$ Shilin A.A. Strengthening of reinforced concrete structures using composite materials / A.A. Shilin, V.A. Pshenichny, D.V. Kartuzov. - Moscow: Publishing House «Stroiizdat», $2004-144$ p. 
opening width up to $0.3 \mathrm{~mm}$ were revealed on the surface of these beams (Fig. 3).

According to the results of visual and instrumental examination and verification calculations of beam structures and floor slabs, it was found that the technical condition of the structures does not provide sufficient bearing capacity for their normal and safe further operation for its intended purpose. Therefore, specialists of SE «Research institute of building production» (Kyiv) were recommended to perform their strengthening.

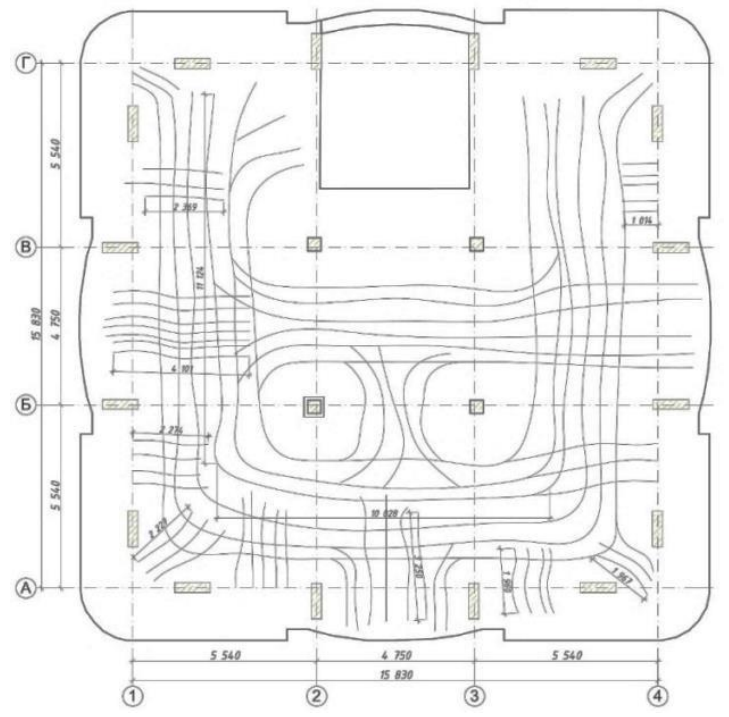

Fig. 1. Diagram of the location of cracks found on the lower surface (ceiling) of the ceiling

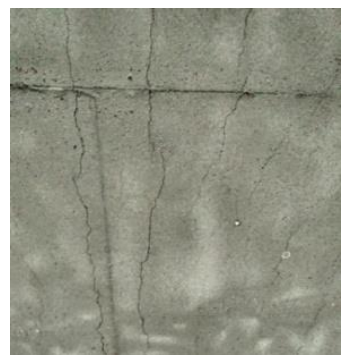

a)

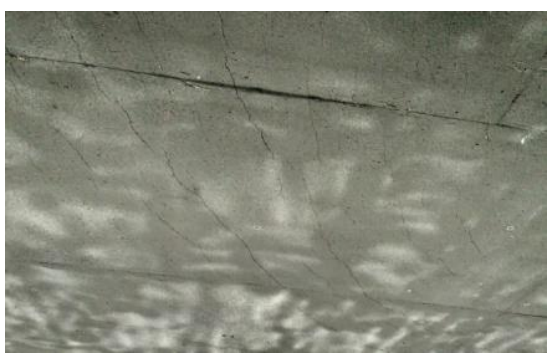

б)

Fig. 2. Cracks on the surface of the slab: a-longitudinal; b-envelope 


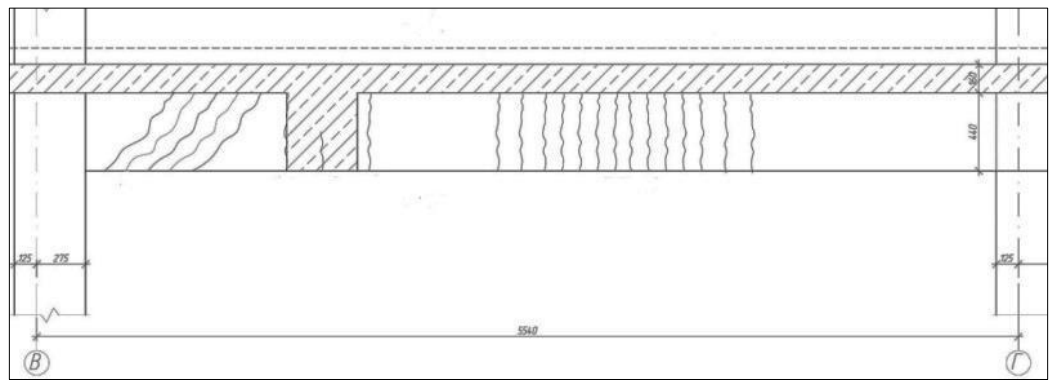

Fig. 3. The scheme of the location of cracks on the surface of the longitudinal beam of the ceiling above the basement

At the first stage of research of efficiency and choice of an optimum variant of strengthening of designs by external reinforcement a number of experimental researches in laboratory of GP «NIISP»was carried out. The purpose of such studies, as noted above, was to test the effectiveness of strengthening reinforced concrete beam structures system using carbon fibers and the search for alternative systems to it from cheaper materials. The load-bearing capacity of reinforced concrete beam structures for bending was adopted as a criterion of efficiency.

During the research the reinforcement of the stretched zone of reinforced concrete beams was performed in the following ways:

- carbon fiber bonding;

- gluing fiberglass threads;

- bonding of steel strips;

- bonding of steel parts.

The study used beams in the form of reinforced concrete partitions type $1 \mathrm{~PB}$ 10-1 with the following characteristics: dimensions (length $\mathrm{x}$ width $\mathrm{x}$ height) 1030x120x65 mm; weight of the structure-20 kg; concrete class C12 / 15.

Reinforcement of beams with carbon fiber was performed using materials and technology of MapeWrap C UNI-AX system developed by the manufacturer «MAPEI» (test series No. 4) ${ }^{5}$. The use of the system MapeWrap C UNI-AX provides the following technological sequence: preparation of the surface cross members; the preparation and application MapeWrap Primer 1; the preparation and application MapeWrap 11; preparation and application MapeWrap 31; preparation and impregnate the fabric with MapeWrap 31; stacking and smoothing carbon fiber MapeWrap C UNIAX; applying a second layer of MapeWrap 31.

\footnotetext{
${ }^{5}$ Mapewrap C UNI-AX. Coating high-strength carbon fiber unidirectional. [e-resource]. Available at: http://rosmax.com.ua
} 
Other three alternative ways of strengthening of beam designs are executed according to recommendations of the producer of composite materials LLC «Composite» ${ }^{6}$ and on the basis of the previous similar researches (series of tests № $1,2,3)^{7}$. Strengthening of beams is executed on the following technology: cleaning of a surface; Drawing a layer of a polymeric composition «Konsolid$1 »$; drawing of glue «Edmok»; gluing of elements of strengthening.

The test was performed for four series of ways to strengthen structures with external reinforcement (Fig. 4, 5).

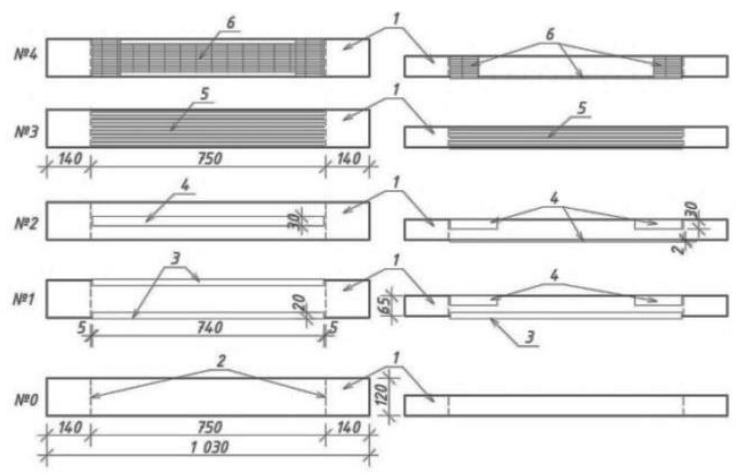

Fig. 4. Schemes of strengthening of beams by external reinforcement:

1-a beam; 2 - places of a support; 3 -a steel corner; 4-a steel strip;

5-glass fiber; 6-carbon fiber; No. 0... No. 4-test series numbers

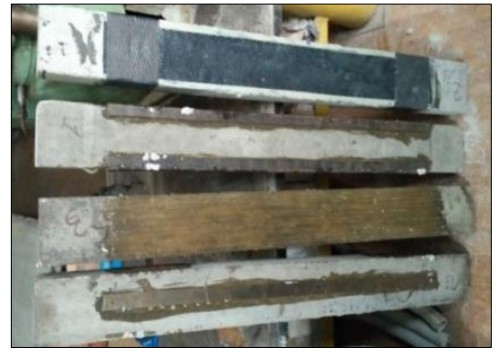

Fig. 5. Strengthening of beams by the given options of external reinforcement

\footnotetext{
${ }^{6}$ Technological map for the restoration of brick and reinforced concrete structures and their protection / LLC «Composite». - Kyiv, 2009. - 7 p.

${ }^{7}$ Savyovsky V. V. Strengthening of reinforced concrete beam structures by external reinforcement / V.V. Savyovsky, O.S. Molodid, N.O. Malets // Development Management of complex systems. - 2017 - № 29. - pp. $198-204$.
} 
Test series № 0 is made for control beams. With beams did not perform any action-reinforcement is not added. In the test series № $1,20 \times 3 \mathrm{~mm}$ steel corners were glued to the lower corners of the beams, and steel plates were glued to the upper support zones. For series of tests № 2 to the lower the surface beams and in the upper priopornikh zones glued steel swathe of wide $30 \mathrm{~mm}$ and, measuring $2 \mathrm{~mm}$. Series of tests № 3 envisaged the spraying on the lower and lateral the surface beams adhesive mortar, in which evenly «dipped» 10 threads fiberglass on an effort, and on 5 threads on lateral the surface. In series of tests № 4 strengthening met system MapeWrap C UNI-AX with gluing carbon fiber on the lower the surface beams with an additional gluing all carbon fiber wound on lateral the surface in priopornikh zones.

Elements of external reinforcement were not brought to $5 \mathrm{~mm}$ to the support zone.

Test on installation of bearing capacity of beams on a bend is carried out on the hydraulic press P-50 through $96 \mathrm{~h}$ after gluing of external reinforcement.

Tests are executed, for the static scheme-as for beams on two supports with a span of $750 \mathrm{~mm}$. loading of beams was carried out through two steel tubes equidistant from supports and among themselves, that is two concentrated efforts (Fig. 6).

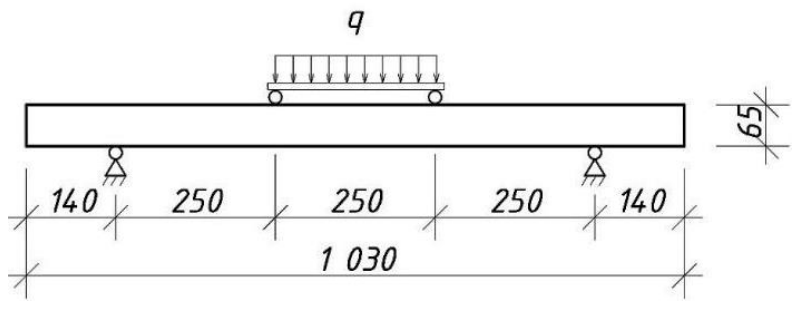

\section{Fig. 6. Scheme of loading of the tested reinforced concrete beams}

Step-by-step loading of beams with an increase in load by $50 \mathrm{~kg}$ at each step with an endurance for $3 \mathrm{~min}$. the Tests were carried out until the complete destruction of the beams. The results of experimental studies are given in table. 1. The nature of the destruction of beams reinforced in various ways is shown in Fig. 7. 
The results of experimental studies

to establish the destructive force of beams

\begin{tabular}{|c|c|c|c|}
\hline $\begin{array}{c}\text { № } \\
\text { series } \\
\text { of tests }\end{array}$ & $\begin{array}{l}\text { Average } \\
\text { breaking } \\
\text { force, } \mathrm{kg}\end{array}$ & $\begin{array}{l}\text { The average } \\
\text { breaking } \\
\text { force, } \%\end{array}$ & Character of destruction for beams \\
\hline 0 & 407 & 100 & \\
\hline 1 & 1400 & 343,9 & $\begin{array}{l}\text { Tearing off the edges of the corners } \\
\text { with the formation of an inclined crack in the } \\
\text { support zone. }\end{array}$ \\
\hline 2 & 1200 & 294,8 & $\begin{array}{l}\text { Destruction of concrete in the middle of } \\
\text { beams. The plate is intact. }\end{array}$ \\
\hline 3 & 1300 & 319,4 & $\begin{array}{l}\text { Destruction on the middle of beams with } \\
\text { breaking of glass fiber on the lower plane }\end{array}$ \\
\hline 4 & 1700 & 417,6 & $\begin{array}{l}\text { Destruction of the beam in the supporting zone } \\
\text { with the formation of an inclined crack }\end{array}$ \\
\hline
\end{tabular}

The analysis of the results of experimental studies showed that the highest load-bearing capacity of beam structures was achieved in variants with external reinforcement by MapeWrap C UNI-AX system with carbon fiber $(1700 \mathrm{~kg}$ ) (study series № 4). Also, the average breaking force increased more than three times with the reinforcement of structures with metal corners and fiberglass and amounted to $1400 \mathrm{~kg}$ and $1300 \mathrm{~kg}$ for research series № 1 and № 3. A slightly worse result was obtained when reinforcing the beams with steel plates where the average breaking force was $1200 \mathrm{~kg}$.

In the second stage of efficiency studies scientific studies were carried out to assess the economic feasibility of using a specific method of strengthening the floor slabs. For this purpose the following methods of amplification were compared: supply of metal beams with the installation of additional supports, external amplification under the «MAPEI» technology and external reinforcement under the previously researched and proposed technologies. Provided research and comparison of technical and economic indicators for overlappings with area of $250 \mathrm{~m}^{2}$, where outer loop is based on the piers and columns support it in the middle (Fig. 8, 9).

The main technical and economic performance indicators (TEP) selected for comparison: cost of materials for amplification, complexity, wages and performance duration.

By the first method, the reinforcement of the floor slab is provided by the supply of metal beams with the installation of additional supports (columns) (Fig. 8). Since, when performing amplification by the indicated method, the height of the room is significantly reduced, but in this case it is not acceptable, therefore this method is considered only for the purpose of comparison of the TEP. 

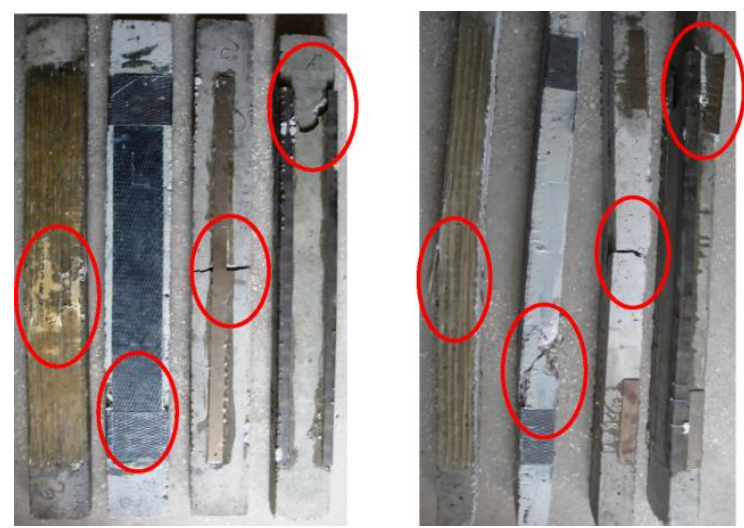

Fig. 7. Character of destruction of the beams strengthened by various methods with reflection of places of destruction

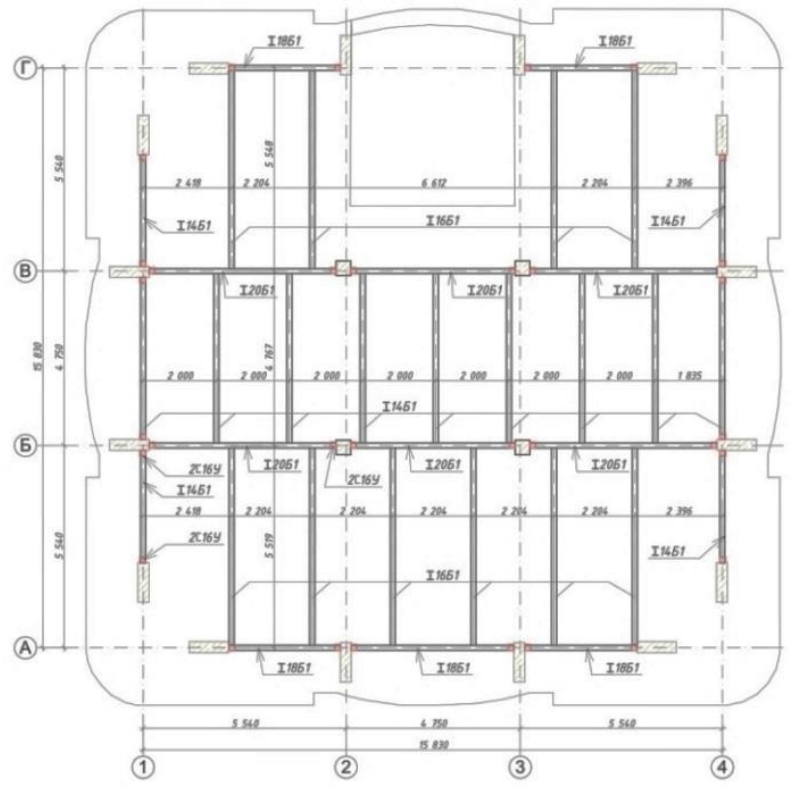

Fig. 8. Scheme of reinforcing elements of the floor slab according to the method of supplying steel beams with the installation of additional columns 
The project provides for the installation of rigidly fixed metal columns (two 16U wires welded in a box) to existing reinforced concrete vertical structures in the areas shown in Fig. 8. On the columns are laid and welded longitudinal double T-beams 18B1 and 20B1 on the lower shelves of which through inserts (if necessary) are laid and welded transverse double T-beams 14B1 and 16B1.

The following methods provide external reinforcement of slabs made of reinforced concrete, such as bonding metal plates or carbon fiber on the stretched zones. This will allow increasing bearing capacity of the plate and reducing deflection. The areas for adhesion of strips for external reinforcement are shown in the schematic of the reinforcement elements (Fig. 9).

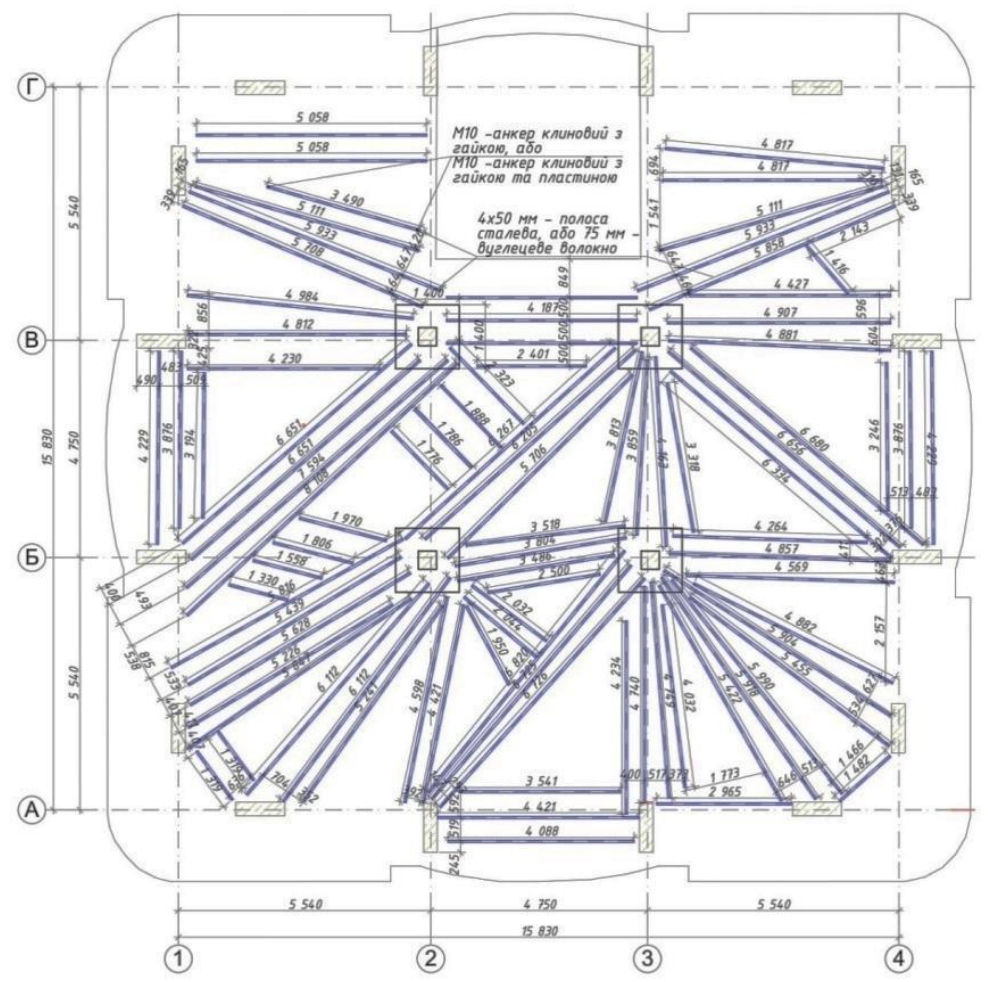

Fig. 9. The layout of the elements of reinforcement of the floor slab with the method of external amplification (MAPEI technology, metal plates, or carbon fiber under developed technology) 
By the second method, the reinforcement of the floor slab is performed according to the technology of the «MAPEI» company. Prior to the beginning of the reinforcement work, future carbon fiber bonding sites should be cleaned from the "glossy» surface using a sandblasting device, or a grinding machine with a special disk to clear concrete surfaces. This technology provides for priming the concrete surface to strengthen the foundations with composition MapeWrap Primer 1, bonding unidirectional carbon fiber MapeWrap C UNI-AX with adhesive MapeWrap 21. The ends of the strips of carbon fiber mechanically fixed with metal plates and bolts M10.

In the third method is scheduled to perform enhancement of the plate by sticking metal plates to its stretched areas. Firstly, the cleaning of the places for gluing plates is carried out according to the technology described above. Subsequently, the place of gluing the plates and $10 \mathrm{~mm}$ on each side outside each plate is impregnated with the composite grounding foundation «Consolid 1» manufactured by LLC «COMPOSIT». At least 24 hours later bonding of metal plates $(4 \times 50 \mathrm{~mm})$ is executed on an epoxy based adhesive «EDMOK» produced by LLC «COMPOSIT». At the ends the plates are fixed with wedge anchors M10. Plates are pre-wiped to shine and degreased.

By the fourth method, the reinforcement is performed by gluing of strips of unidirectional carbon fiber on the stretched zones. Before the beginning of the gluing work, place intended for bonding the fiber is prepared, namely, the surface is cleaned and «Consolid 1» foundation is applied as described in the previous method. After 24 hours «EDMOK» adhesive is applied on the prepared surface and strips of carbon fiber are «drown» in it with a spatula. In 5-10 minutes, another layer of «EDMOC» adhesive is applied to the surface of the fiber so that it completely percolates the fiber and remains on the surface. The ends of carbon fiber strips are mechanically fixed with metal plates and bolts M10.

First of all, we are going to establish the cost of the materials necessary for the work on reinforcing the floor slab for each of the technologies described. The total cost of materials and equipment is determined by the formula (1):

$$
\mathrm{P}_{\mathrm{M}}=\sum_{\mathrm{i}=1}^{\mathrm{n}}\left(\rho_{\text {мп }} \cdot \mathrm{Q}_{\text {мп }}\right),
$$

where $\rho_{\mathrm{Mn}}-$ total value of the products of each individual material;

$\mathrm{Q}_{\mathrm{Mn}}$ - the volume of each individual material.

For the first method is defined the overall length of each type of steel elements and multiplied by its density, double T-beams $14 \mathrm{~B} 1=571.41 \mathrm{~kg}$, 
$16 \mathrm{~B} 1=698.5 \mathrm{~kg}, 18 \mathrm{~B} 1=256.41 \mathrm{~kg}, 20 \mathrm{~B} 1=659.2 \mathrm{~kg}$; Channel for columns $16 \mathrm{U}=2905,32 \mathrm{~kg}$.

Consequently, the total cost of metal elements is:

$$
\begin{aligned}
P_{\mathrm{M}}=23,2 \mathrm{UAH} / \mathrm{kg}(571,4 \mathrm{~kg}+698,5 \mathrm{~kg}+256,4 \mathrm{~kg}+659,2 \mathrm{~kg}+2905,3 \mathrm{~kg}) \\
=118106,5 \mathrm{UAH},
\end{aligned}
$$

where 23,2 is the cost of one kilogram of steel constructions.

For the second method it is established that in order to strengthen the stretched zones of the slab floor, $376 \mathrm{rm}$ of carbon fiber MapeWrap C UNIAX 300/10 is required, which, with a strip width of $10 \mathrm{~cm}$ has a density of $300 \mathrm{~g} / \mathrm{m}$. The cost of such carbon fiber is $154.7 \mathrm{UAH} / \mathrm{rm}$.

Thus, the cost of fiber needed to strengthen the entire plate is:

$$
\mathrm{P}_{\mathrm{M}}=154,7 \mathrm{UAH} / \mathrm{rm} \times 376,0 \mathrm{rm}=58167,2 \mathrm{UAH} .
$$

The MapeWrap Primer 1 priming fluid consumption is $11.28 \mathrm{~kg}$. With the price of $1 \mathrm{~kg}$ of grounding 740,76 UAH, its total cost will be:

$$
\mathrm{P}_{\mathrm{M}}=740,7 \mathrm{UAH} / \mathrm{kg} \times 11,28 \mathrm{~kg}=8355,7 \mathrm{UAH} .
$$

For adhesion of carbon fiber, adhesive MapeWrap 21 is used with a total consumption for an overlapping amounting $37.6 \mathrm{~kg}$. The price of glue is $553,97 \mathrm{UAH} / \mathrm{kg}$, so its total cost will be:

$$
\mathrm{P}_{\mathrm{M}}=553,9 \mathrm{UAH} / \mathrm{kg} \times 37,6 \mathrm{~kg}=20829,2 \mathrm{UAH} .
$$

For the third method of amplification, analyzed in this article, is needed $581.0 \mathrm{~kg}$ of steel strip $4 \times 50 \mathrm{~mm}$ at its price of $23.2 \mathrm{UAH} / \mathrm{kg}$. Consequently, the total cost of the steel strip for reinforcing the plate is:

$$
\mathrm{P}_{\mathrm{M}}=23,2 \mathrm{UAH} / \mathrm{kg} \times 581,0 \mathrm{~kg}=13479,2 \mathrm{UAH} .
$$

The total cost of the grounding «Consolid 1» will be:

$$
\mathrm{P}_{\mathrm{M}}=227 \mathrm{UAH} / 1 \times 9,51=2156,5 \mathrm{UAH}
$$

with its need amounting 9.5 liters and a price of $227 \mathrm{UAH} / \mathrm{liter}$.

The total cost of adhesive "EDMOC», which will be used when amplifying the plate according to this technology, is: 


$$
\mathrm{P}_{\mathrm{M}}=288,0 \mathrm{UAH} / \mathrm{kg} \times 28,2 \mathrm{~kg}=8121,6 \mathrm{UAH}
$$

at its price $288 \mathrm{UAH} / \mathrm{kg}$ and need $28.2 \mathrm{~kg}$.

For the fourth method of amplification requires $376.0 \mathrm{rm}$ of unidirectional carbon fiber with density of $300 \mathrm{~g} / \mathrm{rm}$ and a width of a strip of $10 \mathrm{~cm}$, as indicated above, at a price of $125.0 \mathrm{UAH} / \mathrm{m}$. Under these conditions, the total cost of fiber for the plate reinforcement will make:

$$
\mathrm{P}_{\mathrm{M}}=125,0 \mathrm{UAH} / \mathrm{rm} \times 376,0 \mathrm{rm}=47000,0 \mathrm{UAH} .
$$

The total cost of the grounding «Consolid $1 »$ is:

$$
\mathrm{P}_{\mathrm{M}}=227,0 \mathrm{UAH} / \mathrm{l} \times 15,71=3564,0 \mathrm{UAH}
$$

with its need for 15.7 liters and a price of 227.0 UAH/liter.

The total cost of adhesive «EDMOC», used when amplifying the plate according to this technology, is:

$$
\mathrm{P}_{\mathrm{M}} \mathrm{P}_{\mathrm{M}}=288,0 \mathrm{UAH} / \mathrm{kg} \times 75,2 \mathrm{~kg}=21657,6 \mathrm{UAH}
$$

As the need for glue «EDMOC» is $75.2 \mathrm{~kg}$, and its price $-288 \mathrm{UAH} / \mathrm{kg}$.

The calculation of the cost of materials needed to reinforce the floor slab is given in Table 2 and in Fig. 10.

The second phase of the study TEP provides establishment of complexity and amount of wages for performed work at strengthening plates with different technologies. The complexity is determined by the normative values in accordance with the DBN, SGS, DSTU and Unified Norms and Prices, as well as by the values obtained by the results of their own timing. All labor complexity values are summarized in Table 2 .

Wages, salaries of workers performing amplification are defined in UAH based on the data book «Pricing in construction». The indicated costs are $20.5 \mathrm{UAH} /$ hour for the worker with a grade of 3.8. The calculation of labor and wages is shown in Table 2. The histogram of labor intensity (Fig. 11) and wages (Fig. 12) on the reinforcement of the plate by different technologies is constructed according to the data of Table 3. 
Table 2

Cost of materials for reinforcement of floor slab by different methods

\begin{tabular}{|c|c|c|c|c|}
\hline \multirow{2}{*}{ Name of material } & \multicolumn{4}{|c|}{ Cost of materials, UAH } \\
\cline { 2 - 5 } & $\begin{array}{c}\text { supply of } \\
\text { metal } \\
\text { beams }\end{array}$ & $\begin{array}{c}\text { «MAPEI» } \\
\text { technology }\end{array}$ & $\begin{array}{c}\text { gluing } \\
\text { metal } \\
\text { plates }\end{array}$ & $\begin{array}{c}\text { gluing } \\
\text { carbon } \\
\text { fiber }\end{array}$ \\
\hline Metal beams and columns & 118106,5 & - & - & - \\
\hline $\begin{array}{c}\text { MapeWrap C UNI-AX } \\
\text { 300/10 }\end{array}$ & - & 58167,2 & - & - \\
\hline MapeWrap Primer 1 & - & 8355,7 & - & - \\
\hline MapeWrap 21 & - & 20829,2 & - & - \\
\hline Steel strip 50×4 & - & - & 13479,2 & - \\
\hline Consolid & - & - & 2156,5 & 3564,0 \\
\hline EDMOK & - & - & 8121,6 & 21657,6 \\
\hline Carbon fiber 300/10 & - & - & - & 47000,0 \\
\hline Anchor M10 & - & 516 & 516 & 516 \\
\hline Steel strip for mechanical \\
fastening & - & 345 & - & 345 \\
\hline Total cost & $\mathbf{1 1 8 1 0 6 , 5}$ & $\mathbf{8 8 2 1 3 , 1}$ & $\mathbf{2 3 7 5 7 , 3}$ & $\mathbf{7 3 0 8 2 , 6}$ \\
\hline
\end{tabular}

Pм, UAH

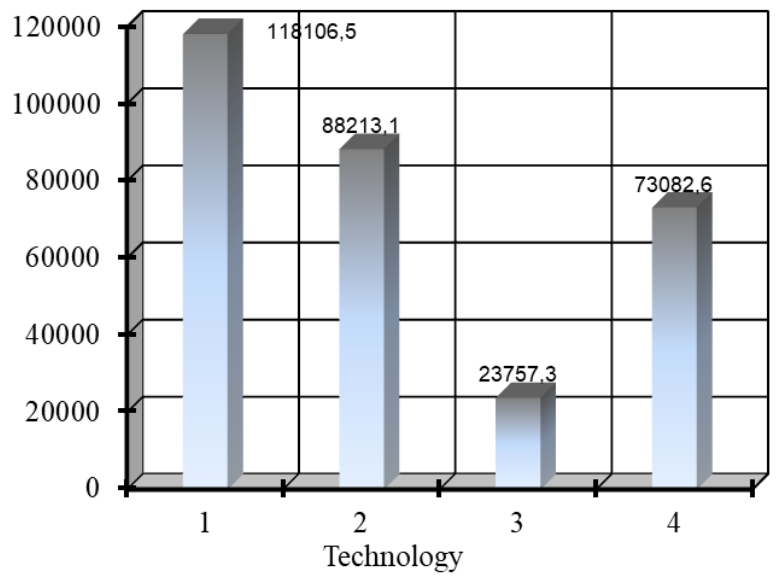

Fig. 10. Cost of materials for reinforcement of floor slab:

1 - supply of metal beams; 2 - «MAPEI» technology;

3 - gluing of metal plates; 4 - gluing carbon fiber

Table 3 


\section{Calculation of labor complexity of reinforcing overlapping slabs}

by different methods and wages for these works

\begin{tabular}{|c|c|c|c|c|c|c|c|c|}
\hline \multirow[b]{3}{*}{ Working operation } & \multicolumn{8}{|c|}{$\begin{array}{l}\text { The complexity and wages to enhance the floor slab according } \\
\text { to the appropriate technology }\end{array}$} \\
\hline & \multicolumn{2}{|c|}{$\begin{array}{c}\text { supply of metal } \\
\text { beams }\end{array}$} & \multicolumn{2}{|c|}{$\begin{array}{l}\text { «MAPEI» } \\
\text { technology } \\
\end{array}$} & \multicolumn{2}{|c|}{$\begin{array}{c}\begin{array}{c}\text { gluing metal } \\
\text { plates }\end{array} \\
\end{array}$} & \multicolumn{2}{|c|}{$\begin{array}{c}\text { gluing carbon } \\
\text { fiber }\end{array}$} \\
\hline & 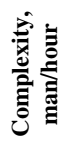 & 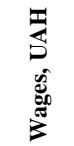 & 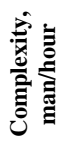 & 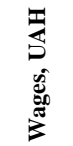 & 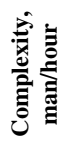 & 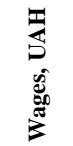 & 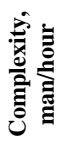 & 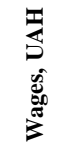 \\
\hline $\begin{array}{c}\text { Painting of metal } \\
\text { elements }\end{array}$ & 28,5 & 584,2 & - & - & - & - & - & - \\
\hline $\begin{array}{c}\text { Cutting, assembly } \\
\text { and welding }\end{array}$ & 478,2 & 9803,1 & - & - & - & - & - & - \\
\hline Cleaning the surface & - & - & 8,8 & 180,4 & 8,6 & 176,3 & 8,8 & 180,4 \\
\hline Priming the surface & - & - & 10,2 & 209,1 & 9,6 & 196,8 & 10,2 & 209,1 \\
\hline Technological break & & & & & & $24 \mathrm{r}$ & & \\
\hline $\begin{array}{l}\text { Gluing Carbon Fiber } \\
\text { / Metal Plates }\end{array}$ & - & - & 55,4 & 1135,7 & 336,3 & 6894,1 & 55,4 & $\begin{array}{c}1135, \\
7\end{array}$ \\
\hline $\begin{array}{c}\text { Fixing ends of } \\
\text { stripes with anchors }\end{array}$ & - & - & 19,2 & 393,6 & 17,6 & 360,8 & 19,2 & 393,6 \\
\hline Total & 506,7 & 10387,3 & 93,6 & 1918,8 & 372,1 & 7628,0 & 93,6 & 1918,8 \\
\hline
\end{tabular}

Q, man/hour

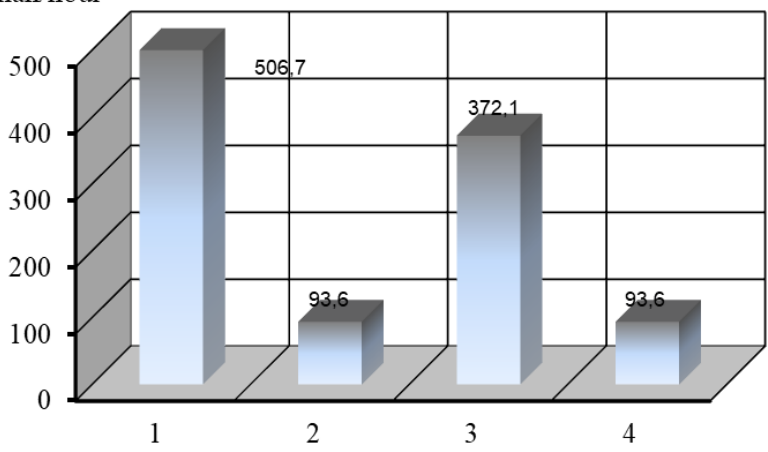

Technology

Fig. 11. The complexity of work on reinforcement of the floor slab:

1 - supply of metal beams; 2 - «MAPEI» technology;

3 - gluing of metal plates; 4 - gluing carbon fiber 


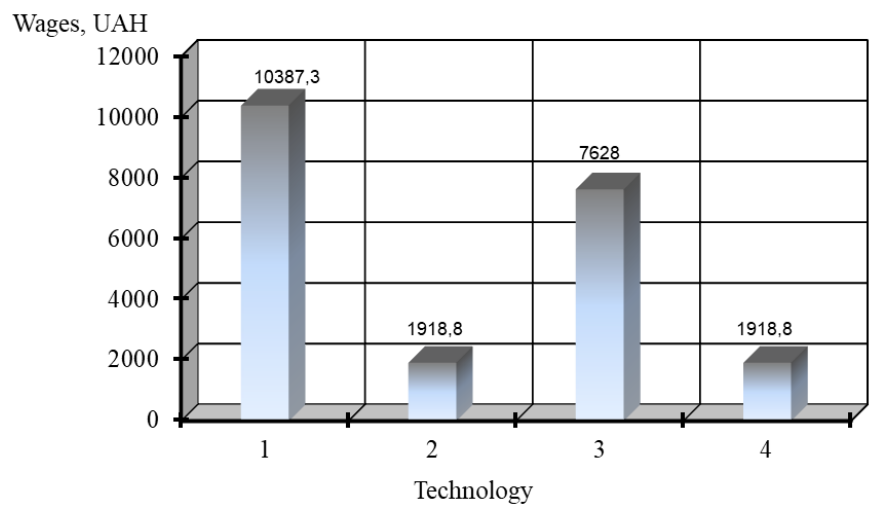

Fig. 12. Wages for strengthening slabs:

1 - supply of metal beams; 2 - «MAPEI» technology;

3 - gluing of metal plates; 4 - gluing carbon fiber

The duration of the process of reinforcing the floor slab (Fig. 13) is determined by adding the duration of the work operations with the length of the technological breaks between them according to the Table 3 . It is taken into account that the painting of metal constructions and surface cleaning is carried out by one worker, the assembly and welding work is carried out by three workers, and all other processes are performed by two workers.

$\mathrm{T}$, changes

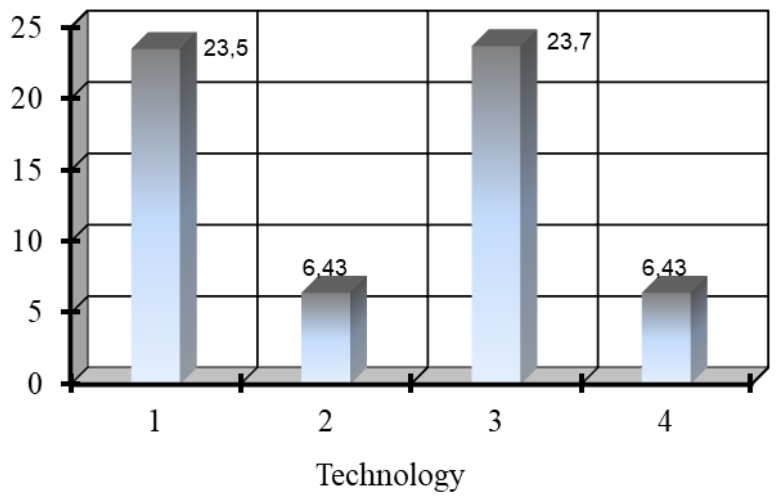

Fig. 13. Duration of work on reinforcement of floor slab:

1 - supply of metal beams; 2 - «MAPEI» technology;

3 - gluing of metal plates; 4 - gluing carbon fiber 
According to the study of technical and economic performance of different amplification technologies applied to the same floor slab it was found that the cost of materials, complexity and wages for performing such works on reinforcing floor slab with the amplification method of supply of metal structures is the highest. At the same time labor intensity, wages and the duration of work execution are the lowest with the reinforcement of the floor slabs by the technology of the company MAPEI and the bonding of carbon fiber by the developed technology. The cost of materials for reinforcing the slab by the developed technology, namely, bonding of steel plates is the lowest, but the complexity, wages and length of work under such technology is much higher than other investigated technologies of reinforcement by external enhancement.

The research results are a strong argument in choosing a particular way of strengthening of structures, namely, one of the components of a variant feasibility study of the decisions taken.

\section{SUMMARY}

Amplification of beam structures is usually performed in several classical ways, in particular: increase in cross-section due to build-up; changing the static scheme of work due to the installation of laggings, beam knees, racks, etc. However, the arrangement of additional reinforcement structures leads to a decrease in inter-floor space, an increase in the load on the supports and foundations and changes in structural and planning decisions of the interior space of the building. An alternative to these methods of reinforcement of beam structures is external reinforcement namely high-tension cloths, plates or strips that are bonded with special adhesives to the surfaces of structures. However, domestic scientific-technical and normative literature actually leaves such methods of amplification out of its attention. That is why a number of experimental studies were carried out to determine efficiency of reinforcing structures under MAPEI technology with the use of carbon fiber and in order to find alternative to domestic technologies. In alternative studies the authors used fiberglass, steel strips and steel angles bonded with special adhesives of domestic production. The efficiency criterion of technologies being tested was adopted bending load capacity of amplified beam structures made of reinforced concrete.

The results of experimental studies found that reinforcement technology MAPEI by applying carbon fiber increases carrying capacity of beams to $417.6 \%$ compared with non-enhanced beams. At the same time, amplification of beams with steel angles increased their bearing capacity by $343.9 \%$, with steel plates - by $294.8 \%$, and with fiberglass - by $319.4 \%$.

The obtained results indicate high efficiency of the investigated methods of strengthening for beam structures and build up the direction of further 
research of organizational and technological solutions for the implementation of external additional reinforcement of beam constructions.

Also the paper presents the results of the study of technical and economic indicators of various methods of reinforcing monolithic reinforced concrete slab, namely: the supply of metal beams with the installation of additional supports, external reinforcement of stretched zones using MAPEI technology, adhesion of metal plates and carbon fiber to the developed technology. It is established that the highest indicators of the cost of materials, labor intensity and wages for the execution of works relate to the option of reinforcing the floor slab by supplying metal structures, and the lowest indicators have options for reinforcing the floor slabs using MAPEI technology and bonding carbon fiber under the developed technology. The cost of materials for reinforcing the plate in the developed technology with the adhesion of steel plates is the lowest, but complexity, wages and the duration of the work on this technology are much higher than other studied technologies of external reinforcement.

\section{REFERENCES}

1. DSTU B V.3.1-2: 2016. Repair and strengthening of bearing and enclosing building constructions and foundations of buildings and structures [Effective from 2017-04-01]. - Kyiv: SE “UkrNDNTS", 2017. - 72 p.

2. Ignatova I.V. Strengthening of concrete structures with the help of a polymer-silicate composition / I.V. Ignatova // Building Constructions: a collection of scientific works. - Kyiv, SE "NDIBK", 2011. - Issue number 75, Book 2. - pp. 614-621.

3. Rekomendatsyy po vosstanovlenyyu y usylenyyu polnosbornykh zdanyy polymerrastvoramy. [Recommendations for the restoration and strengthening of full-fledged buildings by polymer materials] TbilZNIIEP. Moscow: Stroyizdat, 1990. $-160 \mathrm{p}$.

4. Savyovsky V. V. reconstruction of buildings and constructions / V. V. Savyovsky - Kiev, «Lira-K», 2018. -320 p.

5. Savyovsky V. V. Strengthening of reinforced concrete beam structures by external reinforcement / V.V. Savyovsky, O. S. Molodid, N.O. Malets // Development Management of complex systems. - 2017 № 29. - pp. 198-204.

6. Technological map for the restoration of brick and reinforced concrete structures and their protection / LLC «Composite». - Kyiv, 2009. -7 p.

7. Shagin A.L. Reconstruction of buildings and structures / A.L. Shagin, Yu. V. Bondarenko, D.F. Goncharenko. - Moscow, Higher Education, 1991. $-352 \mathrm{p}$. 
8. Shilin AA. Strengthening of reinforced concrete structures using composite materials / A.A. Shilin, V.A. Pshenichny, D.V. Kartuzov. Moscow: Publishing House «Stroiizdat», 2004 - 144 p.

9. Klebearmierung [e-resource]. - Available at: http://www.diamontag.ch.

10. Mapewrap C UNI-AX. Coating high-strength carbon fiber unidirectional. [e-resource]. - Available at: http://rosmax.com.ua

11. Minnaugh P. L. The experimental behavior of steel fiber reinforced polymer retrofit measures: thesis master of Science / Patrick Lucien Minnaugh; University of Pittsburgh school of engineering. Pittsburgh, $2006-113$ p.

12. Obaidat Y. T. Structural retrofitting of reinforced concrete beams using carbon fibre reinforced polymer: Licentiate Dissertation / Yasmeen Taleb Obaidat; Division of Structural Mechanics, LTH, Lund University. Sweden, May, 2010 - 88 p. ISSN 0281-6679

13. Grigorovsky P. E. Strengthening of beam structures by external reinforcement by the method of adhesion of high-strength fabrics / P. E. Grigorovsky, O. S. Molodid, R. O. Plokhuta // Building Production. 2016 - No. 61/1. - pp. 13-18.

\section{Information about the author: Molodid O. S.,}

Ph.D. in Engineering, Associate Professor, Assistant Professor at the Construction Production Technology Department,

Kyiv National University of Construction and Architecture 31, Povitroflotskyi Ave., Kyiv, 03037, Ukraine 